\title{
Proinflammatory effects of S100A8/A9 via TLR4 and RAGE signaling pathways in BV-2 microglial cells
}

\author{
LI MA $^{1 *}$, PENG SUN ${ }^{2 *}$, JIAN-CHENG ZHANG ${ }^{1}$, QING ZHANG ${ }^{1}$ and SHANG-LONG YAO ${ }^{1}$ \\ Departments of ${ }^{1}$ Anesthesiology and Intensive Care Medicine and ${ }^{2}$ Emergency, Union Hospital, \\ Tongji Medical College, Huazhong University of Science and Technology, Wuhan, Hubei 430022, P.R. China
}

Received September 11, 2016; Accepted April 24, 2017

DOI: $10.3892 /$ ijmm.2017.2987

\begin{abstract}
S100A8/A9, a heterodimer of the two calciumbinding proteins S100A8 and S100A9, has emerged as an important proinflammatory mediator in acute and chronic inflammation. However, whether S100A8/A9 is implicated in microglial-induced neuroinflammatory response remains unclear. Here, we found that S100A8/A9 significantly increased the secretion of proinflammatory cytokines including tumor necrosis factor- $\alpha$ (TNF- $\alpha$ ) and interleukin-6 (IL-6) in cultured BV-2 microglial cells. Inhibition of the Toll-like receptor 4 (TLR4) and the receptor for advanced glycation end-products (RAGE) with C225 and a RAGE-blocking antibody, respectively significantly reduced the secretion of TNF- $\alpha$ and IL-6 from S100A8/A9-stimulated BV-2 microglial cells. Furthermore, S100A8/A9 markedly enhanced the nuclear translocation of NF- $\mathrm{kB}$ p65 and the DNA-binding activities of NF- $\mathrm{KB}$ in BV-2 microglial cells, and suppression of ERK and JNK/MAPK signaling pathways by PD98059 or SP600125 significantly inhibited NF- $\mathrm{KB}$ activity and the release of TNF- $\alpha$ and IL-6 in the S100A8/A9-treated BV-2 microglial cells. Our data also showed that inhibition of $\mathrm{NF}-\mathrm{\kappa B}$ with pyrrolidine dithiocarbamate (PDTC) significantly reduced the secretion of TNF- $\alpha$ and IL- 6 from BV-2 microglial cells treated with
\end{abstract}

Correspondence to: Dr Qing Zhang or Professor Shang-Long Yao, Department of Anesthesiology and Intensive Care Medicine, Union Hospital, Tongji Medical College, Huazhong University of Science and Technology, 1277 Jiefang Avenue, Wuhan, Hubei 430022, P.R. China E-mail: zqann_126@126.com

E-mail: ysltian@163.com

${ }^{*}$ Contributed equally

Abbreviations: CNS, central nervous system; DAMP, damageassociated molecular pattern; DAPI, 6-diamidino-2-phenylindole; ERK, extracellular signal-regulated kinase; IL-6, interleukin-6; JNK, c-Jun N-terminal kinase; LPS, lipopolysaccharide; MAPK, mitogen-activated protein kinase; NF- $\kappa \mathrm{B}$, nuclear factor- $\kappa \mathrm{B}$; RAGE, receptor for advanced glycation endproducts; TLR4, Toll-like receptor 4; TNF- $\alpha$, tumor necrosis factor- $\alpha$

Key words: mitogen-activated protein kinase, microglia, neuroinflammation, nuclear factor- $\kappa \mathrm{B}, \mathrm{S} 100 \mathrm{~A} 8 / \mathrm{A} 9$
S100A8/A9. Taken together, our data suggest that S100A8/A9 acts directly on BV-2 microglial cells via binding to TLR4 and RAGE on the membrane and then stimulates the secretion of proinflammatory cytokines through ERK and JNK-mediated NF- $\kappa$ B activity in BV-2 microglial cells. Targeting S100A8/A9 may provide a novel therapeutic strategy in microglial-induced neuroinflammatory diseases.

\section{Introduction}

S100A8 and S100A9 (also termed MRP8 and MRP14), which are called damage-associated molecular pattern (DAMP) molecules, play critical roles in the inflammatory process. The preferential forms of the S100A8/A9 heterodimers are associated with the pathogenesis of various diseases, and coupled with an inflammatory component, which is primarily released from activated or necrotic neutrophils and monocytes/macrophages $(1,2)$. In the central nervous system (CNS), S100A8/A9 is implicated in the pathology of numerous inflammatory diseases including Alzheimer's disease, traumatic brain injury and stroke (3-5).

Previous studies have indentified both the Toll-like receptor 4 (TLR4) and receptor for advanced glycation end products (RAGE) as activated receptors of S100A8/A9 (6-8). Previous studies have shown that activated microglia express high levels of TLR4 and RAGE in response to neuroinflammation (9-12). Microglial activation plays a pivotal role during the development and progression of neurodegenerative diseases based on its great capacity for secreting proinflammatory cytokines, such as tumor necrosis factor- $\alpha$ (TNF- $\alpha$ ) and interleukin-6 (IL-6), resulting in acute inflammation (13). As an endogenous ligand of TLR4 and RAGE (14), S100A8/A9 also amplifies the production of proinflammatory cytokines and contributes to CNS injury $(2,15)$. However, whether S100A8/A9 could activate BV-2 microglial cells by binding to TLR4 and/or RAGE on the membrane and subsequently mediate the inflammatory response through inflammatory cytokines or chemokines remains unclear (12,17-20).

It is well known that NF- $\mathrm{kB}$ as a pleiotropic regulator is involved in the production of many proinflammatory cytokines and enzymes (21). NF- $\mathrm{KB}$ is also a central regulator of microglial responses to stimuli (21). In general, activation of $\mathrm{NF}-\mathrm{\kappa B}$ in microglia leads to neuronal injury and promotes the development of neurodegenerative disorders such as stroke, 
severe epileptic seizures, and also chronic neurodegenerative conditions, including Alzheimer's disease, Parkinson's disease and Huntington's disease (22). Increasing evidence has shown that the activated NF- $\mathrm{BB}$-modulated proinflammatory effects of microglia are regulated by mitogen-activated protein kinase (MAPK) signaling pathways, including the c-Jun N-terminal protein kinase $(\mathrm{JNK})$, the $\mathrm{p} 38$ mitogen-activated protein kinase (MAPK) and the extracellular signal related kinase (ERK) (22-25).

The purpose of this in vitro study was to investigate whether S100A8/A9 could activate BV-2 microglial cells by binding to TLR4 and/or RAGE on the membrane and then subsequently amplify the secretion of proinflammatory cytokines through the MAPK/NF- $\mathrm{B}$ signaling pathways in BV-2 microglial cells.

\section{Materials and methods}

Cell culture. The immortalized murine microglial cell line BV-2 was purchased from Cell Resource Centre of Peking Union Medical College (Beijing, China) and maintained in Dulbecco's modified Eagle's medium with F12 (DMEM/F12) and supplemented with $10 \%$ fetal bovine serum (FBS) (both from Gibco, Grand Island, NY, USA), $100 \mathrm{U} / \mathrm{ml}$ penicillin and $100 \mu \mathrm{g} / \mathrm{ml}$ streptomycin at $37^{\circ} \mathrm{C}$ in a humidified atmosphere of $95 \%$ air $5 \% \mathrm{CO}_{2}$. Confluent cultures were passaged by trypsinization. BV-2 cells were seeded onto 24-well culture plates $\left(10^{5}\right.$ cells/well for ELISA, $10^{4}$ cells/well for immunofluorescence), 6 -well plates $\left(2.5 \times 10^{5}\right.$ cells/well for PCR) or $100 \mathrm{~mm}$ culture dishes $\left(1.2 \times 10^{6}\right.$ cells/dish for western blotting and EMSA). BV-2 cells were incubated in the initial experiments with different concentrations $(0.01,0.1$ or $1.0 \mu \mathrm{M})$ of S100A8/A9 (USCN, Wuhan, China). A concentration of $0.1 \mu \mathrm{M}$ S100A8/A9 was used in the subsequent experiments or vehicle $(0.035 \%$ ethanol).

RNA isolation and real-time PCR. Total RNA was extracted from BV-2 microglial cells with TRIzol reagent (Invitrogen, Carlsbad, CA, USA) according to the manufacturers' protocol. Total RNA $(1.0 \mu \mathrm{g})$ was subjected to oligo(dT)-primed RT with ReverTra Ace kit (Toyobo, Osaka, Japan). Real-time PCR was performed for quantitative analysis of IL- 6 and TNF- $\alpha$ mRNA expression using SYBR-Green Real-Time PCR Master Mix (Toyobo, Osaka, Japan) on an MX3000P real-time PCR system (Stratagene, La Jolla, CA, USA). The following primers were used: 5'-CATCTTCTCAAAATTCGAGTGACAA-3' and 5'-TGGGAGTAGACAAGGTACAACCC-3', which amplify the 175-bp product for TNF- $\alpha$; and 5'-TGTCCACCTT CCAGCAGATGT-3' and 5'-AGCTCAGTAACAGTCCGCCT AGA-3', which amplify the 101-bp product for $\beta$-actin; and 5'-ACAACCACGGCCTTCCCTACTT-3' and 5'-CACGATTT CCCAGAGAACATGTG-3', which amplify the 129-bp product for IL-6. Relative gene expression was calculated using the $2^{-\Delta \Delta \mathrm{CT}}$ method.

ELISA for IL- 6 and TNF- $\alpha$. BV-2 microglial cells were stimulated for $12 \mathrm{~h}$ with $166 \mu \mathrm{g} / \mathrm{ml}$ RAGE-blocking antibody (Abcam, Cambridge, UK), $1.0 \mu \mathrm{g} / \mathrm{ml} \mathrm{C} 225$ (inhibitor of TLR4), $20 \mu \mathrm{M}$ PD98059 [inhibitor of extracellular signaling kinase (ERK)], $7 \mu \mathrm{M}$ SB203580 (inhibitor of p38 MAP kinase),
$10 \mu \mathrm{M}$ SP600125 (inhibitor of JNK) or $50 \mu \mathrm{M}$ PDTC (inhibitor of p65 NF- $\kappa$ B) (all from R\&D Systems, ON, Canada) for $1 \mathrm{~h}$ before addition of $0.1 \mu \mathrm{M}$ recombinant S100A8/A9 proteins or $1 \mu \mathrm{g} / \mathrm{ml}$ LPS (Escherichia coli O26:B6; Sigma-Aldrich, St. Louis, MO, USA) in the presence of $25 \mu \mathrm{g} / \mathrm{ml}$ polymyxin B (R\&D Systems), and the culture supernatants were harvested. Levels of IL-6 and TNF- $\alpha$ in $100 \mu 1$ medium were measured by commercial ELISA kits (Boster Biological Technology, Wuhan, China) according to the manufacturer's instructions.

Biochemistry. BV-2 microglial cells were cultured on sterile glass coverslips and treated according to the experimental design. Afterward, the cells were fixed with $4 \%$ paraformaldehyde in phosphate-buffered saline (PBS) and permeabilized with $0.1 \%$ Triton X-100 in PBS. After rinsing, the cells were blocked with $3 \%$ bovine serum albumin (BSA) for $1 \mathrm{~h}$ and incubated with primary antibodies overnight at $4^{\circ} \mathrm{C}$. The primary antibody used was rabbit anti-NF- $\mathrm{B}(1: 1,000$; ab31481; Abcam). After washing, the cells were incubated with FITC-conjugated goat anti-rabbit IgG (1:400; Jackson ImmunoResearch Laboratories, West Grove, PA, USA) for $1 \mathrm{~h}$ and counterstained with 4,6-diamidino-2-phenylindole (DAPI; Roche, Shanghai, China) for the identification of the nuclei. After washing with PBS, the coverslips were mounted with anti-fade mounting medium (Beyotime, Shanghai, China) on slides, and the cells were observed with an Olympus immunofluorescence microscope (Olympus, Tokyo, Japan).

Protein extraction. For making whole cell lysates, the cells were lysed in radioimmune precipitation assay (RIPA) buffer supplemented with protease inhibitor cocktail (Roche). Nuclear and cytoplasmic fractionations were performed with NE-PER nuclear and cytoplasmic extraction reagents (Thermo Scientific, Rockford, IL, USA) according to the manufacturer's instructions.

Western blot analysis. Equal amounts of nuclear or whole cell extracts were electrophoresed on sodium dodecyl sulfate-polyacrylamide gels, and then transferred onto a polyvinylidene difluoride membrane (Millipore, Schwalbach, Germany). The transformed membrane was blocked with 5\% non-fat dry milk in Tris-buffered saline containing 0.05\% Tween-20 (TBST) for $1 \mathrm{~h}$ and incubated with primary antibodies overnight at $4^{\circ} \mathrm{C}$. The primary antibodies used were as follows: rabbit antiNF-кB (1:1,000; ab31481; Abcam), $\beta$-actin (1:1,000; sc-1616; Santa Cruz Biotechnology, Inc., Heidelberg, Germany) and lamin B (1:1,000; 12987-1-AP; Proteintech Group, Chicago, IL, USA). The membrane was washed 3 times with TBST for $10 \mathrm{~min}$ and incubated with anti-rabbit IgG-horseradish peroxidase (1:5,000; Jackson ImmunoResearch Laboratories) at room temperature for $1 \mathrm{~h}$. The Supersignal West Pico chemiluminescent substrate system (Millipore) was used to detect immunoreactive bands. The intensity of the protein bands after western blot analysis was quantifed using Quantity One software version 4.6.3 (Bio-Rad Laboratories, Inc., Hercules, CA, USA) and normalized against proper loading controls.

Electrophoretic mobility shift assay (EMSA). Nuclear protein was harvested, and $10 \mu \mathrm{g}$ of nuclear protein was assayed for $\mathrm{NF}-\mathrm{\kappa B}$ binding activity using radioactive-labeled 
oligonucleotides for the defined $\mathrm{NF}-\kappa \mathrm{B}$ consensus sequence (5'-AGT TGA GGG GAC TTT CCCAGG C-3') at 50,000 cpm (Cerenkov). Binding separation of the protein DNA complexes from unbound DNA by electrophoresis was performed as previously described in detail (26). Nuclear protein after $1 \mathrm{~h}$ of S100A8/A9 treatment and a 200-fold molar excess of unlabeled consensus sequence were used as the specific competitor in the control lane.

Statistical analysis. Data are expressed as means \pm SEM of the indicated number of independent experiments. Statistical significance between multiple groups was analyzed by one-way ANOVA. Least significant difference (LSD) post hoc test was used for multiple comparisons. Statistical analysis was performed using the SPSS software version 13.0 (SPSS, Inc., Chicago, IL, USA). $\mathrm{P}<0.05$ was considered statistically significant.

\section{Results}

Proinflammatory cytokine production by $B V-2$ microglial cells after S100A8/A9 stimulation. In this study, the response of BV-2 microglial cells in culture to S100A8/A9 was evaluated by determining the expression of inflammatory cytokine proteins. As a positive control, LPS at $1 \mu \mathrm{g} / \mathrm{ml}$ significantly increased the production of TNF- $\alpha$ and IL- 6 compared with the control group. S100A8/A9 at $0.01,0.1$ or $1.0 \mu \mathrm{M}$ also significantly increased the production of TNF- $\alpha$ and IL-6 (Fig. 1A and B). There was no difference in the levels of TNF- $\alpha$ and IL- 6 between the $1 \mu \mathrm{g} / \mathrm{ml}$ LPS-treated group and the $0.1 \mu \mathrm{M}$ S100A8/A9-treated group (Fig. 1A and B). Thus, the dose of $0.1 \mu \mathrm{M} \mathrm{S100A8/A9}$ was chosen for further study.

Polymyxin B effectively blocked the TNF- $\alpha$ production induced by $1 \mu \mathrm{g} / \mathrm{ml}$ LPS. However, polymyxin B had no effect on the expression of TNF- $\alpha$ induced by S100A8/A9 in the cultured BV-2 microglial cells, suggesting that the effect of S100A8/A9 on the secretion of proinflammatory cytokines was not blocked by the addition of the LPS inhibitor polymyxin B (Fig. 1C).

Effects of RAGE and TLR4 blockade on S100A8/A9 stimulation. To examine whether S100A8/A9 uses RAGE and TLR4 as signal transducing receptors on BV-2 microglial cells, BV-2 cells were stimulated for $12 \mathrm{~h}$ using $0.1 \mu \mathrm{M}$ S100A8/A9 with or without the RAGE-blocking antibody and TLR4 inhibitor C225. We found that the S100A8/A9-stimulated release of TNF- $\alpha$ and IL- 6 was significantly reduced by blockade of RAGE or TLR4. Therefore, our data suggested that both RAGE and TLR-4 may be relevant to S100A8/A9 stimulation in BV-2 microglial cells (Fig. 2).

Involvement of MAPK signaling pathways and NF- $\kappa B$ activation in S100A8/A9-stimulated secretion of TNF- $\alpha$ and IL-6. EMSA was performed to determine the effect of S100A8/A9 on the activity of $\mathrm{NF}-\kappa \mathrm{B}$ in this study. BV-2 microglial cells were pretreated with vehicle, $0.1 \mu \mathrm{M} \mathrm{S100A8/A9} \mathrm{or} 1 \mu \mathrm{g} / \mathrm{ml}$ LPS for $1 \mathrm{~h}$. We found that the binding activities of NF- $\kappa \mathrm{B}$ were induced by S100A8/A9 treatment, which had an effect similiar to that of LPS treatment (Fig. 3A).

To determine whether S100A8/A9-stimulated secretion of TNF- $\alpha$ and IL- 6 involves NF- $\kappa$ B activation, PDTC, a specific
A

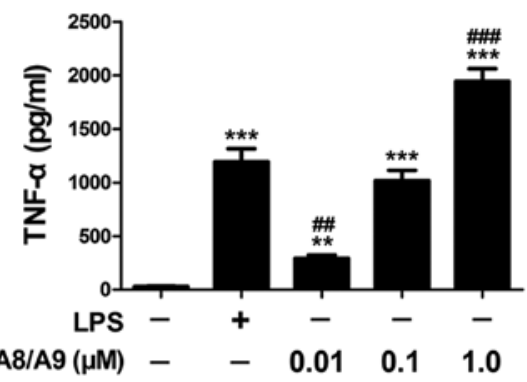

B

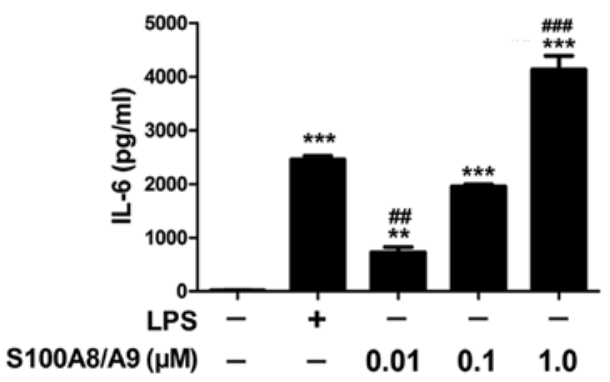

C

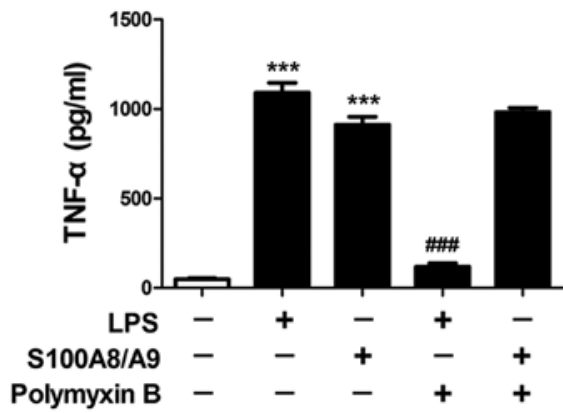

Figure 1. Proinflammatory cytokine production by BV-2 microglial cells after S100A8/A9 stimulation. Effect of lipopolysaccharide (LPS) $(1 \mu \mathrm{g} / \mathrm{ml})$ and $\mathrm{S} 100 \mathrm{~A} 8 / \mathrm{A} 9(0.01-1.0 \mu \mathrm{M})$ on the production of (A) tumor necrosis factor- $\alpha$ (TNF- $\alpha$ ) and (B) interleukin-6 (IL-6) in BV-2 microglial cells. TNF- $\alpha$ and IL- 6 levels were determined by ELISA after $12 \mathrm{~h}$ of incubation. (C) Polymyxin B $(25 \mu \mathrm{g} / \mathrm{ml})$ had no inhibitory effect on S100A8/A9-induced TNF- $\alpha$ expression in BV-2 cells, whereas the effects of LPS were efficiently blocked. TNF- $\alpha$ levels were determined after $12 \mathrm{~h}$ of stimulation by ELISA. Each value represents the mean \pm SEM of three independent experiments. ${ }^{* * *} \mathrm{P}<0.01$ and ${ }^{* * * *} \mathrm{P}<0.001$ compared with the control; ${ }^{\# \#} \mathrm{P}<0.01$ and ${ }^{\# \# \#} \mathrm{P}<0.001$ compared with $0.1 \mathrm{nM} \mathrm{S100A8/A9.}$

inhibitor of $\mathrm{NF}-\kappa \mathrm{B}$, was applied in our study. PDTC treatment significantly reduced the secretion of TNF- $\alpha$ and IL- 6 induced by S100A8/A9 (Fig. 3B and C).

Our data also showed that the expression of IL-6 (Fig. 4A) and TNF- $\alpha$ (Fig. 4B and C) induced by S100A8/A9 were significantly reduced by the addition of PD98059 and SP600125, respectively.

$M A P K$ signaling pathway acts upstream of $N F-\kappa B$ in S100A8/A9 stimulation. To explore whether S100A8/A9-induced secretion of proinflammatory cytokines including TNF- $\alpha$ and IL-6 was through MAPK-mediated activation of NF- $\kappa \mathrm{B}$ in BV-2 microglial cells, a specific ERK inhibitor PD98059, p38 MAP kinase inhibitor SB203580 and JNK inhibitor SP600125 were used. S100A8/A9 treatment caused 

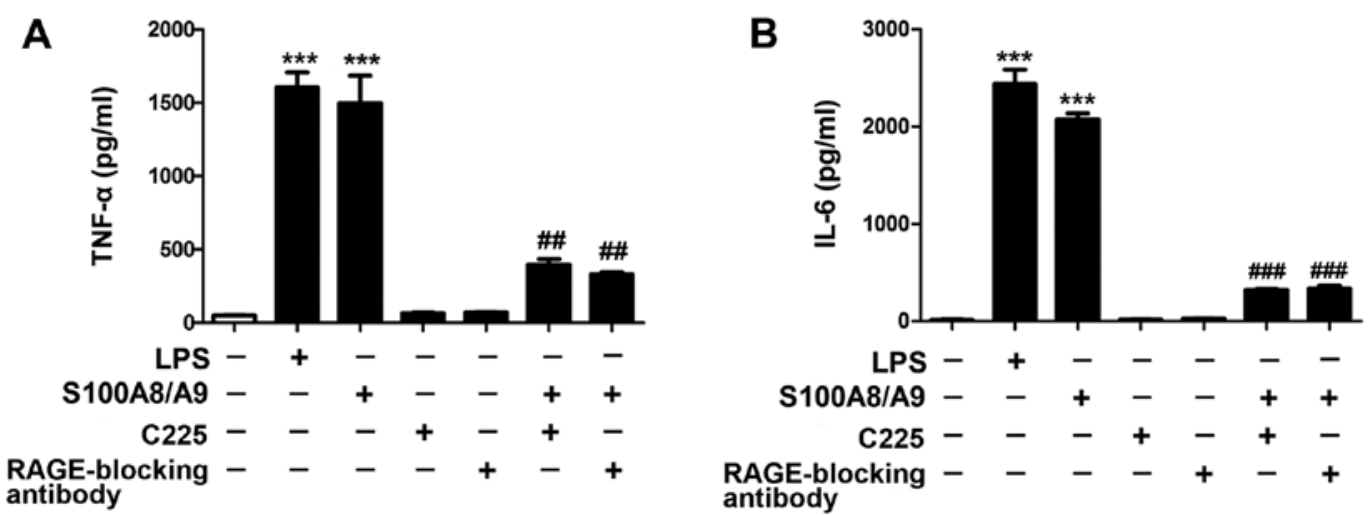

Figure 2. Effects of receptor for advanced glycation endproducts (RAGE) and Toll-like receptor 4 (TLR4) blockade on S100A8/A9 stimulation. (A) Tumor necrosis factor- $\alpha$ (TNF- $\alpha$ ) and (B) interleukin-6 (IL-6), as determined by ELISA, in BV-2 cells after preincubation for $1 \mathrm{~h}$ with $1 \mu \mathrm{g} / \mathrm{ml}$ TLR4 inhibitor (C225) or $166 \mu \mathrm{g} / \mathrm{ml}$ RAGE-blocking antibody followed by $12 \mathrm{~h}$ of stimulation with lipopolysaccharide (LPS) or S100A8/A9 as indicated. Each value represents the mean \pm SEM of three independent experiments. ${ }^{* * *} \mathrm{P}<0.001$ compared with the control; ${ }^{\# \#} \mathrm{P}<0.01$ and ${ }^{\# \# \#} \mathrm{P}<0.001$ compared with S100A8/A9.

A

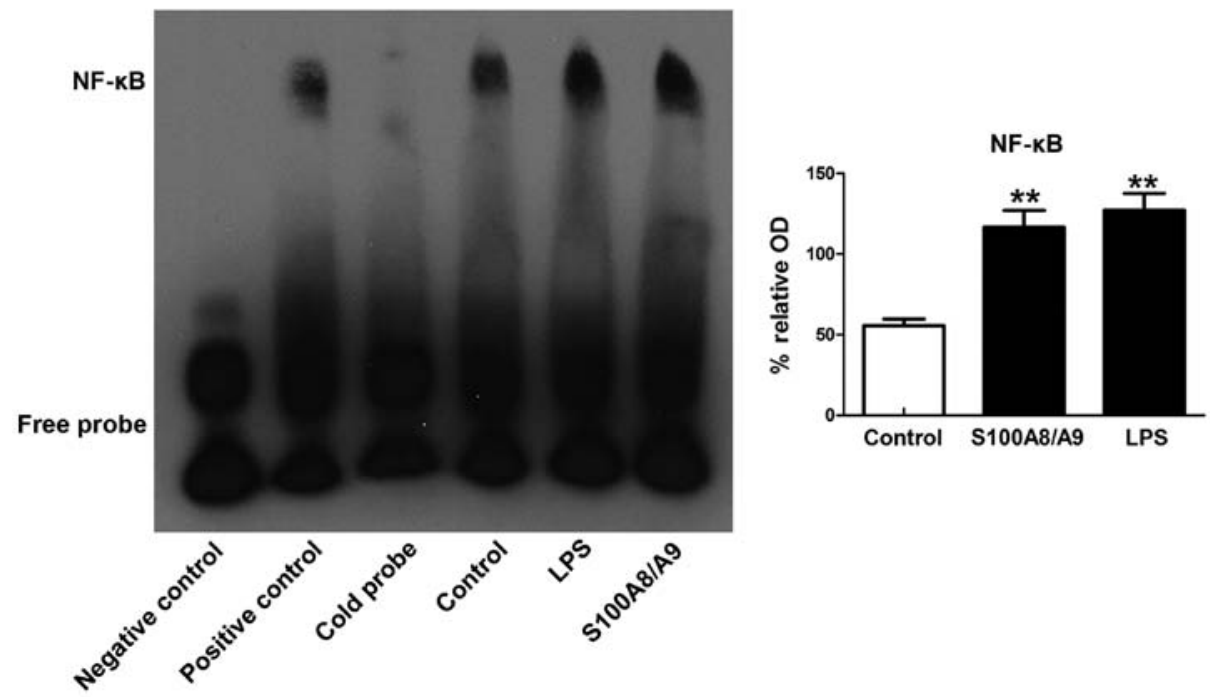

B

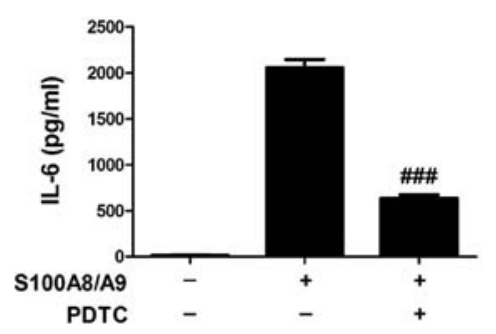

C

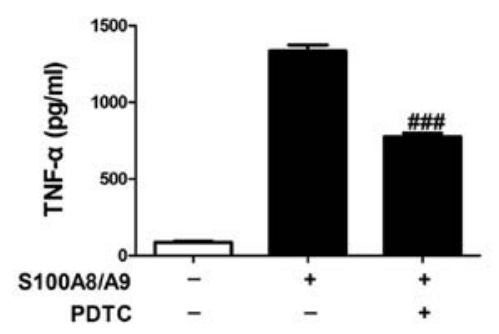

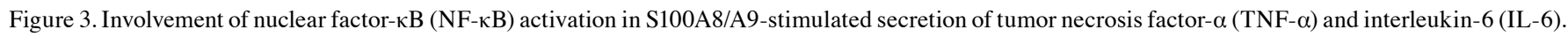
(A) BV-2 cells were stimulated with lipopolysaccharide (LPS) $(1 \mu \mathrm{g} / \mathrm{ml})$ or S100A8/A9 $(0.1 \mu \mathrm{M})$ for $1 \mathrm{~h}$. Nuclear extracts were prepared and used to analyze NF-кB DNA-binding activity by EMSA, as described in Materials and methods. Binding specificity was confirmed by unlabelled probe (100-fold in excess; lane 5) to compete with labelled oligonucleotide. Free-labelled probes are also indicated. (B and C) p65 NF- $\kappa$ B inhibitor PDTC (50 $\mu \mathrm{M})$ was added $1 \mathrm{~h}$ before activation. Results were confirmed by three independent experiments. ${ }^{* *} \mathrm{P}<0.01$ compared with the control; ${ }^{\# \# \#} \mathrm{P}<0.001$ compared with S100A8/A9.

obvious translocation of NF- $\mathrm{KB}$ p65 from the cytoplasm into the nucleus compared with the vehicle treatment, which had an effect similar to that of LPS treatment (Fig. 5A); whereas the presence of PD98059 and SP600125 reduced S100A8/A9-induced translocation of NF- $\mathrm{BB}$ p65 from the cytoplasm into the nucleus (Fig. 5B). To further verify the p65 nuclear translocation data, we analyzed the cells by western blotting and found that pretreatment of cells with PD98059 and SP600125 prevented p65 nuclear localization induced by S100A8/A9 (Fig. 5C and D). 

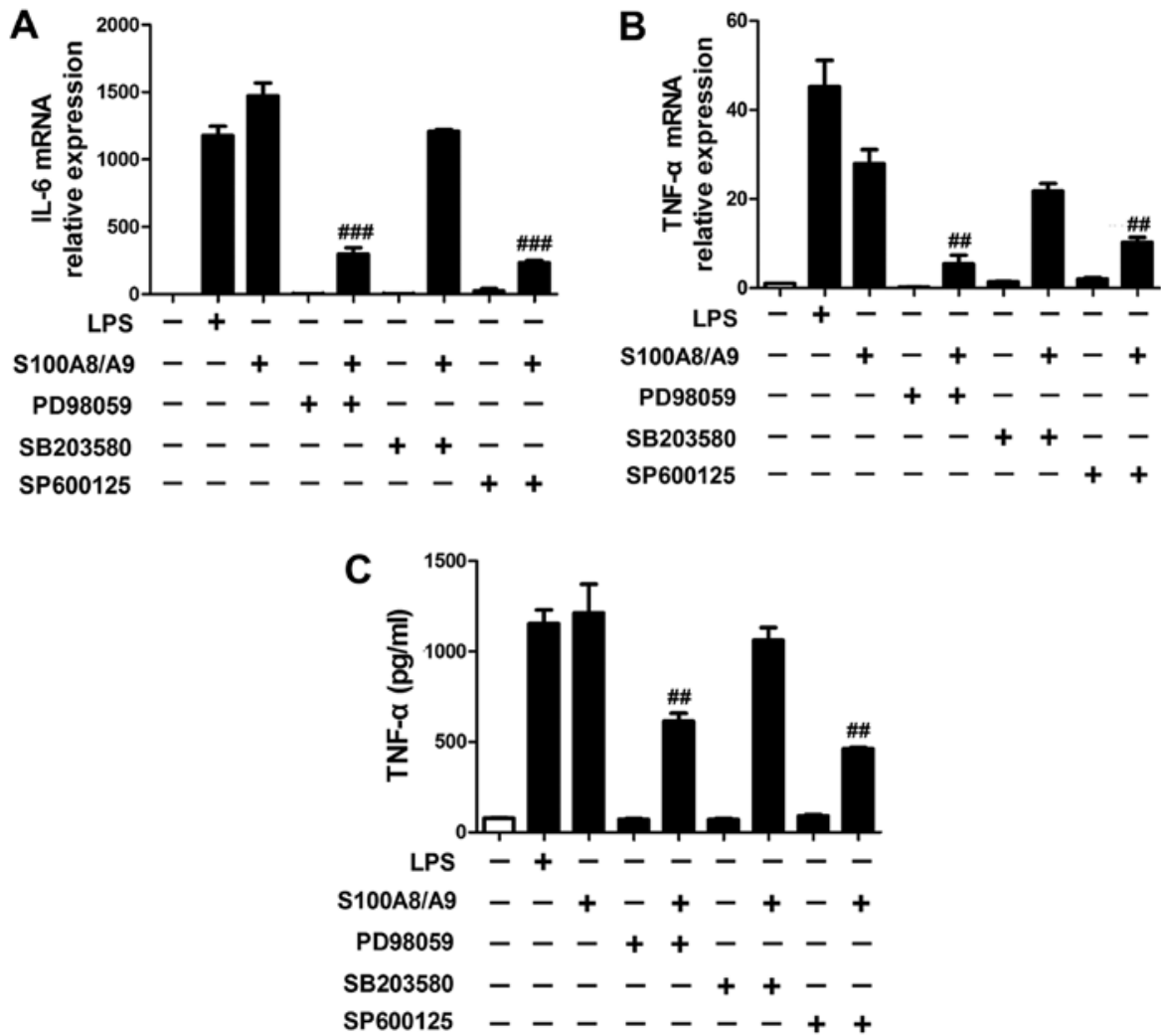

Figure 4. Involvement of mitogen-activated protein kinase (MAPK) signaling pathways in S100A8/A9-stimulated secretion of tumor necrosis factor- $\alpha$ (TNF- $\alpha$ ) and interleukin-6 (IL-6). TNF- $\alpha$ levels determined by (B) ELISA and (C) PCR, and (A) IL-6 levels as determined by PCR in BV-2 cells after $12 \mathrm{~h}$ of stimulation with lipopolysaccharide (LPS) $(1 \mu \mathrm{g} / \mathrm{ml})$ or S100A8/A9 $(0.1 \mu \mathrm{M})$ in the absence or presence of protein kinase inhibitors: extracellular signal-regulated kinase (ERK) inhibitor PD98059 $(20 \mu \mathrm{M})$, p38 inhibitor SB203580 $(7 \mu \mathrm{M})$, c-Jun N-terminal kinase (JNK) inhibitor SP600125 (10 $\mu \mathrm{M})$. Each value represents the mean \pm SEM of three independent experiments. ${ }^{\# \#} \mathrm{P}<0.01$ and ${ }^{\# \# \#} \mathrm{P}<0.001$ compared with S100A8/A9.

\section{Discussion}

This study has the following major findings. i) The proinflammatory effects of S100A8/A9 are partially dependent on the TLR4 and RAGE signaling pathway in microglial BV-2 cells; and ii) S100A8/A9 promotes inflammatory cytokine production via ERK and JNK-mediated NF- $\mathrm{KB}$ activity in microglia.

Activated macrophages and microglia release an array of proinflammatory cytokines, including TNF- $\alpha$ and IL-6, which play important roles in neuroinflammation $(27,28)$. Previous studies have demonstrated that TNF- $\alpha$ and IL-6 play important roles in S100A8/A9-induced inflammation in neutrophils, monocytes, macrophages, human umbilical vein endothelial cells (HUVECs) and keratinocytes (29-33). We demonstrated that S100A8/A9 acted on microglial BV-2 cells and subsequently amplified the secretion of TNF- $\alpha$ and IL-6, as demonstrated by our findings that S100A8/A9 treatment significantly increased the gene and protein expression of TNF- $\alpha$ and IL- 6 in the BV-2 microglial cells.

TLR4, which is mainly expressed in microglia, mediates microglial activation and the expression of proinflammatory mediators in response to a variety of ligands (34). TLR4 signaling has been confirmed to result in the activation of $\mathrm{NF}-\kappa \mathrm{B}$, and subsequently drives the transcriptional abundance of proinflammatory signals, which then activates the innate immune system and produces tissue destruction (35-38). Recently, S100A8/A9, as the endogenous activator of TLR4 signaling, promotes lethal endotoxin-induced shock (6). Thus, our data, which demonstrated that S100A8/A9 contributed to inflammation via TLR4, further revealed that neuroinflammation and ischemic brain injury is modulated by TLR4 (39-41). However, S100A8/A9 not only activates TLR-4, but also RAGE (42). It cannot be excluded that further receptors besides TLR4 may be involved in S100A8/A9-mediated inflammation. Our data showed that the S100A8/A9-stimulated secretion of TNF- $\alpha$ and IL- 6 was also significantly reduced by the blockade of RAGE. Therefore, both RAGE and TLR4 may be relevant to S100A8/A9-induced inflammation in BV-2 microglial cells.

Our subsequent results demonstrated that S100A8/A9 had a strong enhancement effect on inflammatory signaling pathways including NF- $\kappa \mathrm{B}$ and MAPK. Likewise, activation of NF- $\mathrm{KB}$ in microglia contributes to neuronal injury and plays a crucial role in the development of neurodegenerative disorders (22). NF- $\kappa \mathrm{B}$ is also a central regulator of microglial responses to activating stimuli, including cytokines (21). Evidence has shown that the MAPK signaling pathway, such as JNK, p38 MAPK and ERK, play important roles in the activation of NF- $\mathrm{KB}$ in microglial-induced inflammation $(23,25,26)$. However, whether the MAPK signaling pathway is involved in the activation of NF- $\mathrm{KB}$ in activated microglia stimulated by S100A8/A9 is unclear. In the present study, our data showed that S100A8/A9 treatment markedly enhanced the nuclear translocation of NF- $\mathrm{KB}$ p 65 and the DNA-binding activities of NF- $\kappa \mathrm{B}$ in BV-2 microglial cells. S100A8/A9-induced activation of NF- $\kappa B$ and secretion of proinflammatory cytokines TNF- $\alpha$ and IL-6 were attenuated 

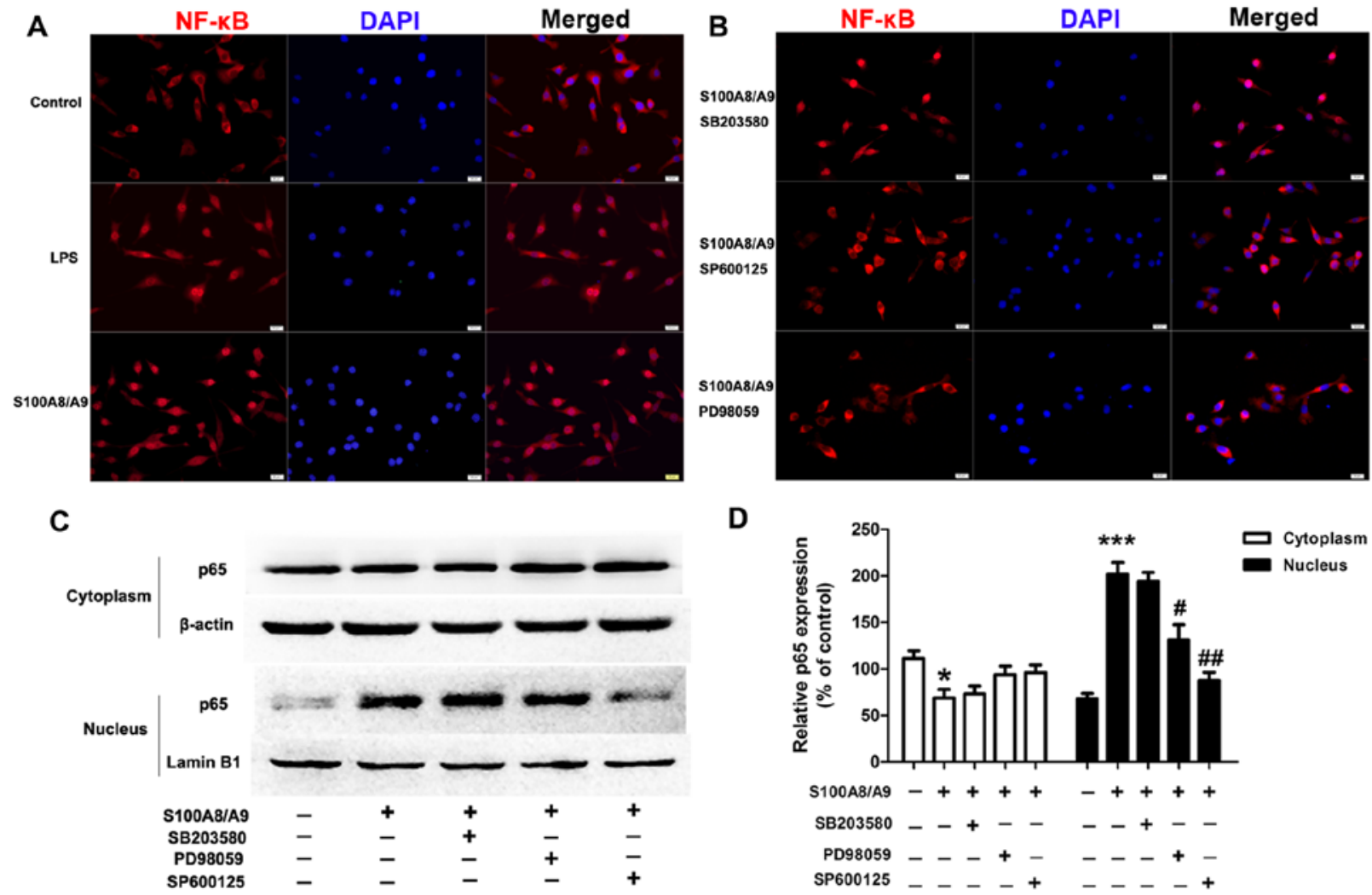

Figure 5. Mitogen-activated protein kinase (MAPK) signaling pathway acts upstream of nuclear factor- $\mathrm{B}$ (NF- $\mathrm{\kappa B}$ ) in S100A8/A9 stimulation. (A) BV-2 cells were stimulated with lipopolysaccharide (LPS) $(1 \mu \mathrm{g} / \mathrm{ml})$ or S100A8/A9 $(0.1 \mu \mathrm{M})$. Subcellular location of the p65 subunit was assessed using immunofluorescence assay $60 \mathrm{~min}$ after activation. (B) BV-2 cells were stimulated with S100A8/A9 $(0.1 \mu \mathrm{M})$ in the presence of PD98059 $(20 \mu \mathrm{M})$, SB203580 $(7 \mu \mathrm{M})$, SP600125 $(10 \mu \mathrm{M})$ that were added 60 min before activation. Subcellular location of the p65 subunit was assessed using immunofluorescence assay 60 min after activation. (C and D) Western blot analysis and quantitative data for cytoplasmic and nuclear p65 in BV-2 cells stimulated with S100A8/A9 (0.1 $\mu \mathrm{M})$ in the presence of PD98059 $(20 \mu \mathrm{M}), \mathrm{SB} 203580(7 \mu \mathrm{M})$ and SP600125 $(10 \mu \mathrm{M})$. Data are presented as mean \pm SEM of three independent experiments. ${ }^{*} \mathrm{P}<0.05$ and ${ }^{\#} \mathrm{P}<0.01$ compared with S100A8/A9; ${ }^{*} \mathrm{P}<0.05$ and ${ }^{* * *} \mathrm{P}<0.001$ compared with the control.

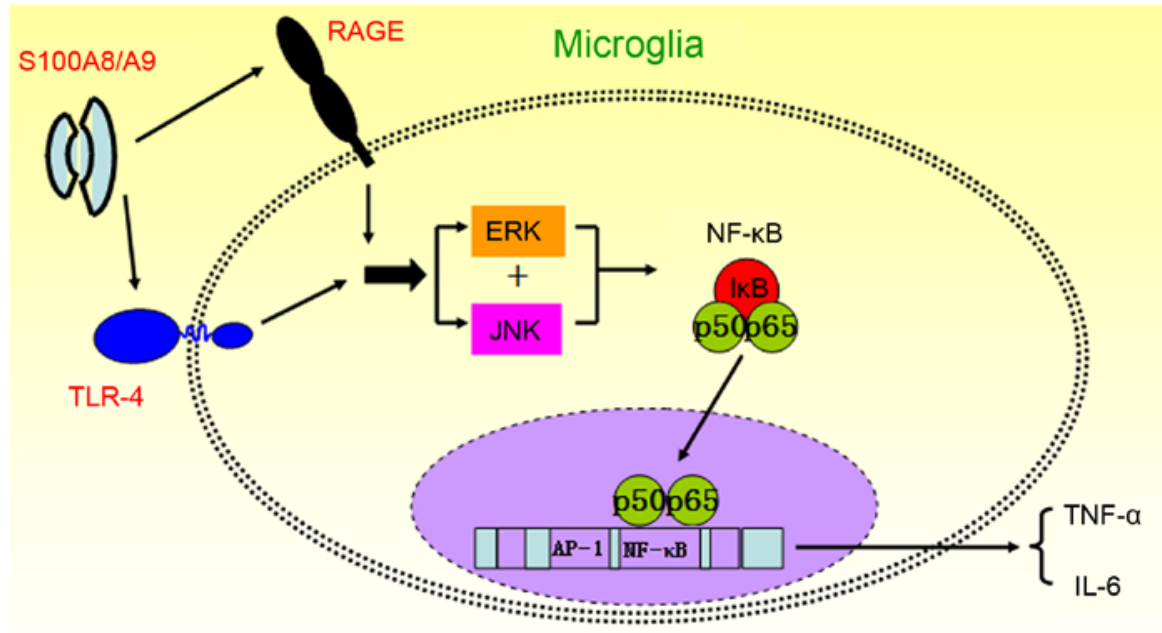

Figure 6. Proinflammatory response of the S100A8/A9 contribution to microglial activation. S100A8/A9 activated microglia via binding the receptor for advanced glycation endproducts (RAGE) and Toll-like receptor 4 (TLR4) on the membrane and promoted the production of proinflammatory cytokines in microglia through the activation of c-Jun N-terminal kinase (JNK)/nuclear factor- $\mathrm{KB}(\mathrm{NF}-\mathrm{\kappa B})$ and extracellular signal-regulated kinase (ERK)/NF- $\mathrm{kB}$ signaling pathways.

by the suppression of ERK and JNK signaling pathways by PD98059 and SP600125, respectively. The data indicate that the ERK and JNK signaling pathways are essential to the activation of NF- $\mathrm{KB}$ in S100A8/A9-induced inflammation. In addition, our data also showed that inhibition of activation of
NF- $\kappa$ B reduced S100A8/A9-induced secretion of TNF- $\alpha$ and IL- 6 from cultured BV-2 microglial cells. Taken together, our results indicate that the ERK/NF- $\kappa B$ and JNK/NF- $\kappa B$ signaling pathways are involved in S100A8/A9-induced inflammation in BV-2 microglial cells. 
Notably, both TLR4 and RAGE inhibitors caused complete inhibition of S100A8/A9-mediated proinflammatory cytokine expression, respectively. Boyd et al also demonstrated that activated TLR4 gives rise to an upregulation of S100A8/A9 expression earlier in cardiomyocytes (19). When S100A8/A9 was overexpressed in prostate cancer cells, NF- $\kappa$ B and MAPK also remained activated (43). It provides one possibility that a positive-feedback loop may exist both upstream and downstream of S100A8/A9. In regards to S100A8/A9 or other ligands, activated RAGE also leads to further enhancement of S100A8/A9 production, and creates a putative positive feedback loop in acute inflammation $(29,44)$. Therefore, blocking TLR4 or RAGE may weaken the positive feedback, and decrease the production of S100A8/A9 obviously, and completely suppress the S100A8/A9-mediated elevation of the cytokines IL-6 and TNF- $\alpha$.

More studies also demonstrated that major risk factors for sepsis, systemic inflammatory response syndrome and septic shock are related to TNF- $\alpha$-independent mechanisms $(45,46)$. However, it was confirmed that a monoclonal antibody to TNF- $\alpha$ given early in the course of severe sepsis has a harmful rather than a beneficial consequence in clinical trials of human sepsis (46). Our present data demonstrated that S100A8/A9 represents a molecular system involved in the pathogenesis of inflammatory response syndrome upstream of TNF- $\alpha$ induction. In consideration of the high abundance of S100A8/A9 in inflammatory diseases, a potential strategy for blocking uncontrolled inflammatory processes may be by targeting these proteins with immune intervention. This strategy may be very specific, as both proteins are secreted via a so-called 'alternative' pathway (47). The inhibition of this alternative transport mechanism should not affect the classical secretion of other proteins through the endoplasmic reticulum and Golgi complex and may thus avoid major side effects.

In conclusion, we found that S100A8/A9 activated microglia via binding RAGE and TLR4 on the membrane and promoted the production of proinflammatory cytokines in microglia through the activation of the ERK/NF- $\kappa \mathrm{B}$ and $\mathrm{JNK} / \mathrm{NF}-\kappa \mathrm{B}$ signaling pathways (Fig. 6). Thus, inhibition of S100A8/A9 release may be another promising therapeutic approach, and S100A8/A9 may represent a useful biomarker and therapeutic target in microglial-mediated neuroinflammatory diseases.

\section{Acknowledgements}

This study was supported by grants from the National Nature Science Foundation of China (nos. 81201444 and 81101401).

\section{References}

1. Nacken W, Roth J, Sorg C and Kerkhoff C: S100A9/S100A8: Myeloid representatives of the $\mathrm{S} 100$ protein family as prominent players in innate immunity. Microsc Res Tech 60: 569-580, 2003.

2. Ehrchen JM, Sunderkötter C, Foell D, Vogl T and Roth J: The endogenous Toll-like receptor 4 agonist S100A8/S100A9 (calprotectin) as innate amplifier of infection, autoimmunity, and cancer. J Leukoc Biol 86: 557-566, 2009.

3. Engel S, Schluesener H, Mittelbronn M, Seid K, Adjodah D, Wehner HD and Meyermann R: Dynamics of microglial activation after human traumatic brain injury are revealed by delayed expression of macrophage-related proteins MRP8 and MRP14. Acta Neuropathol 100: 313-322, 2000.
4. Shepherd CE, Goyette J, Utter V, Rahimi F, Yang Z, Geczy CL and Halliday GM: Inflammatory S100A9 and S100A12 proteins in Alzheimer's disease. Neurobiol Aging 27: 1554-1563, 2006.

5. Ziegler G1, Prinz V, Albrecht MW, Harhausen D, Khojasteh U, Nacken W,Endres M, Dirnagl U, Nietfeld W and Trendelenburg G: Mrp-8 and -14 mediate CNS injury in focal cerebral ischemia. Biochim Biophys Acta 1792: 1198-1204, 2009.

6. Vogl T, Tenbrock K, Ludwig S, Leukert N, Ehrhardt C, van Zoelen MA, Nacken W, Foell D, van der Poll T, Sorg C, et al: Mrp8 and Mrp14 are endogenous activators of Toll-like receptor 4, promoting lethal, endotoxin-induced shock. Nat Med 13: 1042-1049, 2007.

7. Harja E, Bu DX, Hudson BI, Chang JS, Shen X, Hallam K, Kalea AZ, Lu Y, Rosario RH, Oruganti S, et al: Vascular and inflammatory stresses mediate atherosclerosis via RAGE and its ligands in apoE ${ }^{-/}$mice. J Clin Invest 118: 183-194, 2008.

8. Björk P, Björk A, Vogl T, Stenström M, Liberg D, Olsson A, Roth J, Ivars $F$ and Leanderson T: Identification of human S100A9 as a novel target for treatment of autoimmune disease via binding to quinoline-3-carboxamides. PLoS Biol 7: e97, 2009.

9. Hofmann MA, Drury S, Fu C, Qu W, Taguchi A, Lu Y, Avila C, Kambham N, Bierhaus A, Nawroth P, et al: RAGE mediates a novel proinflammatory axis: A central cell surface receptor for S100/calgranulin polypeptides. Cell 97: 889-901, 1999.

10. Donato R: Intracellular and extracellular roles of S100 proteins. Microsc Res Tech 60: 540-551, 2003.

11. Roth J, Vogl T, Sorg C and Sunderkötter C: Phagocyte-specific S100 proteins: A novel group of proinflammatory molecules. Trends Immunol 24: 155-158, 2003.

12. Ghavami S, Rashedi I, Dattilo BM, Eshraghi M, Chazin WJ, Hashemi M, Wesselborg S, Kerkhoff C and Los M: S100A8/A9 at low concentration promotes tumor cell growth via RAGE ligation and MAP kinase-dependent pathway. J Leukoc Biol 83: 1484-1492, 2008.

13. Neumar RW, Nolan JP, Adrie C, Aibiki M, Berg RA, Böttiger BW, Callaway C, Clark RS, Geocadin RG, Jauch EC, et al: Post-cardiac arrest syndrome: Epidemiology, pathophysiology, treatment, and prognostication. A consensus statement from the International Liaison Committee on Resuscitation (American Heart Association, Australian and New Zealand Council on Resuscitation, European Resuscitation Council, Heart and Stroke Foundation of Canada, InterAmerican Heart Foundation, Resuscitation Council of Asia, and the Resuscitation Council of Southern Africa); the American Heart Association Emergency Cardiovascular Care Committee; the Council on Cardiovascular Surgery and Anesthesia; the Council on Cardiopulmonary, Perioperative, and Critical Care; the Council on Clinical Cardiology; and the Stroke Council. Circulation 118: 2452-2483, 2008.

14. Schiopu A and Cotoi OS: S100A8 and S100A9: DAMPs at the crossroads between innate immunity, traditional risk factors, and cardiovascular disease. Mediators Inflamm 2013: 828354, 2013.

15. Ryckman C, Vandal K, Rouleau P, Talbot M and Tessier PA: Proinflammatory activities of S100: Proteins S100A8, S100A9, and S100A8/A9 induce neutrophil chemotaxis and adhesion. J Immunol 170: 3233-3242, 2003.

16. Viemann D, Strey A, Janning A, Jurk K, Klimmek K, Vog1 T, Hirono K, Ichida F, Foell D, Kehrel B, et al: Myeloid-related proteins 8 and 14 induce a specific inflammatory response in human microvascular endothelial cells. Blood 105: 2955-2962, 2005.

17. Bierhaus A, Humpert PM, Morcos M, Wendt T, Chavakis T, Arnold B, Stern DM and Nawroth PP: Understanding RAGE, the receptor for advanced glycation end products. J Mol Med (Berl) 83: 876-886, 2005.

18. Sunahori K, Yamamura M, Yamana J, Takasugi K, Kawashima M, Yamamoto H, Chazin WJ, Nakatani Y, Yui S and Makino H: The S100A8/A9 heterodimer amplifies proinflammatory cytokine production by macrophages via activation of nuclear factor kappa B and p38 mitogen-activated protein kinase in rheumatoid arthritis. Arthritis Res Ther 8: R69, 2006.

19. Boyd JH, Kan B, Roberts H, Wang Y and Walley KR: S100A8 and S100A9 mediate endotoxin-induced cardiomyocyte dysfunction via the receptor for advanced glycation end products. Circ Res 102: 1239-1246, 2008.

20. Turovskaya O, Foell D, Sinha P, Vogl T, Newlin R, Nayak J, Nguyen M, Olsson A, Nawroth PP, Bierhaus A, et al: RAGE, carboxylated glycans and S100A8/A9 play essential roles in colitisassociated carcinogenesis. Carcinogenesis 29: 2035-2043, 2008. 
21. O'Neill LA and Kaltschmidt C: NF-kappa B: A crucial transcription factor for glial and neuronal cell function. Trends Neurosci 20: 252-258, 1997.

22. Mattson MP: NF-kappaB in the survival and plasticity of neurons. Neurochem Res 30: 883-893, 2005.

23. Hu H, Li Z, Zhu X, Lin R and Chen L: Salidroside reduces cell mobility via NF-kappa B and MAPK signaling in LPS-induced BV2 microglial cells. Evid Based Complement Alternat Med 2014: 383821, 2014

24. Jeong YH, Kim Y, Song H, Chung YS, Park SB and Kim HS: Anti-inflammatory effects of $\alpha$-galactosylceramide analogs in activated microglial: Involvement of the p38 MAPK signaling pathway. PLoS One 9: e87030, 2014

25. Yuan L, Wu Y, Ren X, Liu Q, Wang J and Liu X: Isoorientin attenuates lipopolysaccharide-induced proinflammatory responses through down-regulation of ROS-related MAPK/NF- $\kappa \mathrm{B}$ signaling pathway in BV-2 microglial. Mol Cell Biochem 386: 153-165, 2014.

26. Li L, Wu Y, Wang Y, Wu J, Song L, Xian W, Yuan S, Pei L and Shang Y: Resolvin D1 promotes the interleukin-4-induced alternative activation in BV-2 microglial cells. J Neuroinflammation 11: 72, 2014.

27. Manderson AP, Kay JG, Hammond LA, Brown DL and Stow JL: Subcompartments of the macrophage recycling endosome direct the differential secretion of IL-6 and TNFalpha. J Cell Biol 178 57-69, 2007.

28. Zhu J, Qu C, Lu X and Zhang S: Activation of microglial by histamine and substance P. Cell Physiol Biochem 34: 768-780, 2014.

29. Ehlermann P, Eggers K, Bierhaus A, Most P, Weichenhan D, Greten J, Nawroth PP, Katus HA and Remppis A: Increased proinflammatory endothelial response to S100A8/A9 after preactivation through advanced glycation end products. Cardiovasc Diabetol 5: 6, 2006.

30. Ishihara K, Namura T, Murayama $H$, Arai S, Totani M and Ikemoto M: Possibility of formation of the S100A8/A9-proinflammatory cytokine complexes in vivo in acute inflammation and their functional roles. Rinsho Byori 57: 324-331, 2009 (In Japanese).

31. Cesaro A, Anceriz N, Plante A, Pagé N, Tardif MR and Tessier PA: An inflammation loop orchestrated by S100A9 and calprotectin is critical for development of arthritis. PLoS One 7: e45478, 2012.

32. Lee Y, Jang S, Min JK, Lee K, Sohn KC, Lim JS, Im M, Lee HE, Seo YJ, Kim CD, et al: S100A8 and S100A9 are messengers in the crosstalk between epidermis and dermis modulating a psoriatic milieu in human skin. Biochem Biophys Res Commun 423: 647-653, 2012

33. Chimenti MS, Ballanti E, Perricone C, Cipriani P, Giacomelli R and Perricone R: Immunomodulation in psoriatic arthritis: Focus on cellular and molecular pathways. Autoimmun Rev 12: 599-606, 2013
34. McColl BW, Allan SM and Rothwell NJ: Systemic infection, inflammation and acute ischemic stroke. Neuroscience 158: 1049-1061, 2009.

35. Aliprantis AO, Yang RB, Weiss DS, GodowskiP and Zychlinsky A: The apoptotic signaling pathway activated by Toll-like receptor-2. EMBO J 19: 3325-3336, 2000

36. Karikó K, Weissman D and Welsh FA: Inhibition of Toll-like receptor and cytokine signaling - a unifying theme in ischemic tolerance. J Cereb Blood Flow Metab 24: 1288-1304, 2004.

37. Kielian T: Toll-like receptors in central nervous system glial inflammation and homeostasis. J Neurosci Res 83: 711-730, 2006.

38. Mishra BB, Mishra PK and Teale JM: Expression and distribution of Toll-like receptors in the brain during murine neurocysticercosis. J Neuroimmunol 181: 46-56, 2006.

39. Lehnardt S, Massillon L, Follett P, Jensen FE, Ratan R, Rosenberg PA, Volpe JJ and Vartanian T: Activation of innate immunity in the CNS triggers neurodegeneration through a Toll-like receptor 4-dependent pathway. Proc Natl Acad Sci USA 100: 8514-8519, 2003.

40. Kilic U,Kilic E, Matter CM, Bassetti CL and Hermann DM: TLR-4 deficiency protects against focal cerebral ischemia and axotomyinduced neurodegeneration. Neurobiol Dis 31: 33-40, 2008.

41. Marsh BJ, Williams-Karnesky RL and Stenzel-Poore MP Toll-like receptor signaling in endogenous neuroprotection and stroke. Neuroscience 158: 1007-1020, 2009

42. Heizmann CW, Ackermann GE and Galichet A: Pathologies involving the S100 proteins and RAGE. Subcell Biochem 45: 93-138, 2007.

43. Hermani A, De Servi B, Medunjanin S, Tessier PA and Mayer D: S100A8 and S100A9 activate MAP kinase and NF-kappaB signaling pathways and trigger translocation of RAGE in human prostate cancer cells. Exp Cell Res 312: 184-197, 2006.

44. Eggers K, Sikora K,Lorenz M, Taubert T, Moobed M,Baumann G, Stangl K and Stangl V: RAGE-dependent regulation of calciumbinding proteins S100A8 and S100A9 in human THP-1. Exp Clin Endocrinol Diabetes 119: 353-357, 2011.

45. Fisher CJ Jr, Agosti JM, Opal SM, Lowry SF, Balk RA, Sadoff JC, Abraham E, Schein RM and Benjamin E: Treatment of septic shock with the tumor necrosis factor receptor:Fc fusion protein. The Soluble TNF Receptor Sepsis Study Group. N Engl J Med 334: 1697-1702, 1996.

46. Clark MA, Plank LD, Connolly AB, Streat SJ, Hill AA, Gupta R, Monk DN, Shenkin A and Hill GL: Effect of a chimeric antibody to tumor necrosis factor-alpha on cytokine and physiologic responses in patients with severe sepsis - a randomized, clinical trial. Crit Care Med 26: 1650-1659, 1998.

47. Rammes A, Roth J, Goebeler M, Klempt M, Hartmann M and Sorg C: Myeloid-related protein (MRP) 8 and MRP14, calciumbinding proteins of the S100 family, are secreted by activated monocytes via a novel, tubulin-dependent pathway. J Biol Chem 272: 9496-9502, 1997. 